\title{
LA-UR-14-20263
}

Approved for public release; distribution is unlimited.

Title: $\quad$ Development of improved ATF engineering alloy - Mechanical testing of initial alloy

$\begin{array}{ll}\text { Author(s): } & \text { Anderoglu, Osman } \\ & \text { Maloy, Stuart A. } \\ & \text { Lovato, Manuel L. }\end{array}$

Intended for: $\quad$ Report

Issued: $\quad$ 2014-01-15

Disclaimer:

Los Alamos National Laboratory, an affirmative action/equal opportunity employer,is operated by the Los Alamos National

Security, LLC for the National NuclearSecurity Administration of the U.S. Department of Energy under contract DE-AC52-06NA25396.

By approving this article, the publisher recognizes that the U.S. Government retains nonexclusive, royalty-free license to

publish or reproduce the published form of this contribution, or to allow others to do so, for U.S. Government purposes.

Los Alamos National Laboratory requests that the publisher identify this article as work performed under the auspices of the

U.S. Departmentof Energy. Los Alamos National Laboratory strongly supports academic freedom and a researcher's right to publish; as an institution, however, the Laboratory does not endorse the viewpoint of a publication or guarantee its technical correctness. 


\section{Development of improved ATF engineering alloy - Mechanical testing of initial alloy}

\section{O. Anderoglu, M. Lovato, S.A. Maloy}

\section{Los Alamos National Laboratory}

\section{Abstract}

In this report we present the results on the tensile testing of two FeCrAl alloys developed at Oak Ridge National Laboratory.

\section{Introduction}

After the events took place in Fukushima in 2011, improved accident tolerant fuel became a major research area worldwide. The improved accident tolerant fuel systems require enhanced durability under the loss of active cooling for a considerably longer period compared to standard system ( $\mathrm{UO}_{2}$-Zircaloy) while maintaining (or improving) normal fuel performance. One class of the candidate cladding material is FeCrAl alloys.

FeCrAl ferritic alloys are highly resistant to oxidation due to formation of a protective oxide scale at high temperatures [1]. Therefore they are considered as alternative cladding materials for current fleet of light water reactors [2].

The purpose of this report is to present results of mechanical testing performed on the initial FeCrAl ferritic alloys that will perform better under accident scenarios mentioned above. Testing includes room temperature and elevated temperature testing at $\sim 300^{\circ} \mathrm{C}$ and $600^{\circ} \mathrm{C}$.

\section{Experimental}

\subsection{Materials}

The ORNL improved accident tolerant FeCrAl alloys (ORNL-A and ORNL-B) were cast by arc-melting in a back-filled argon gas atmosphere, pre-alloyed with $\mathrm{Y}$, Cr andAl and cast. The nominal chemical compositions are given in Table 1. Figure 1 shows the optical microscopy images of the two alloys. The details of the production steps can be found elsewhere [3].

Table 1 Nominal and analyzed alloy compositions of ORNL nuclear-grade FeCrAl alloys

\begin{tabular}{cccccccccc}
\hline \multirow{2}{*}{ ID } & \multirow{2}{*}{ Status } & $\mathbf{7}$ Composition, wt\% \\
\cline { 2 - 11 } & & Fe & $\mathbf{C r}$ & $\mathbf{A l}$ & $\mathbf{Y}$ & $\mathrm{C}$ & $\mathrm{S}$ & $\mathrm{O}$ & $\mathrm{N}$ \\
\hline \multirow{2}{*}{ ORNL-A } & Aim & 79.85 & 15 & 5 & 0.15 & 0 & 0 & 0 & 0 \\
\cline { 2 - 11 } & Analyzed & $\mathbf{7 9 . 8 7}$ & $\mathbf{1 4 . 9 8}$ & $\mathbf{5 . 0 2}$ & $\mathbf{0 . 0 3 3}$ & 0.0040 & 0.0012 & 0.0013 & 0.0005 \\
\hline \multirow{2}{*}{ ORNL-B } & Aim & 79.35 & 17.5 & 3 & 0.15 & 0 & 0 & 0 & 0 \\
\cline { 2 - 10 } & Analyzed & $\mathbf{7 9 . 5 4}$ & $\mathbf{1 7 . 5 1}$ & $\mathbf{2 . 9 3}$ & $\mathbf{0 . 0 1 7}$ & 0.0050 & 0.0006 & 0.0015 & 0.0011 \\
\hline
\end{tabular}



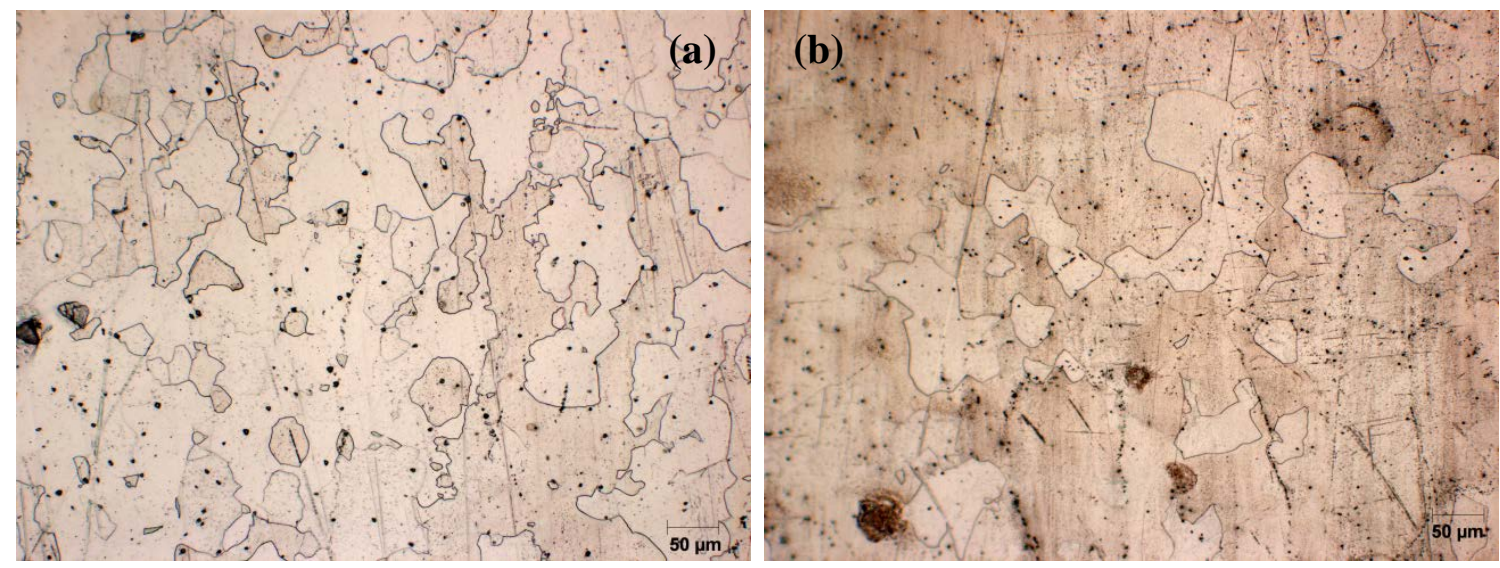

Figure 1 Optical microscopy images of (a) ORNL A (b) ORNL B

\subsection{Tensile tests}

Tensile samples were cut using EDM. The tests were performed at a strain rate of 0.0005 $\mathrm{s}^{-1}$ on an Instron 1125. Compliance was corrected using loading slope. Machine was calibrated using HT-9 samples previously tested. Figure 2 shows the miniature tensile test sample schematic. A minimum of two samples of each alloy were tested.

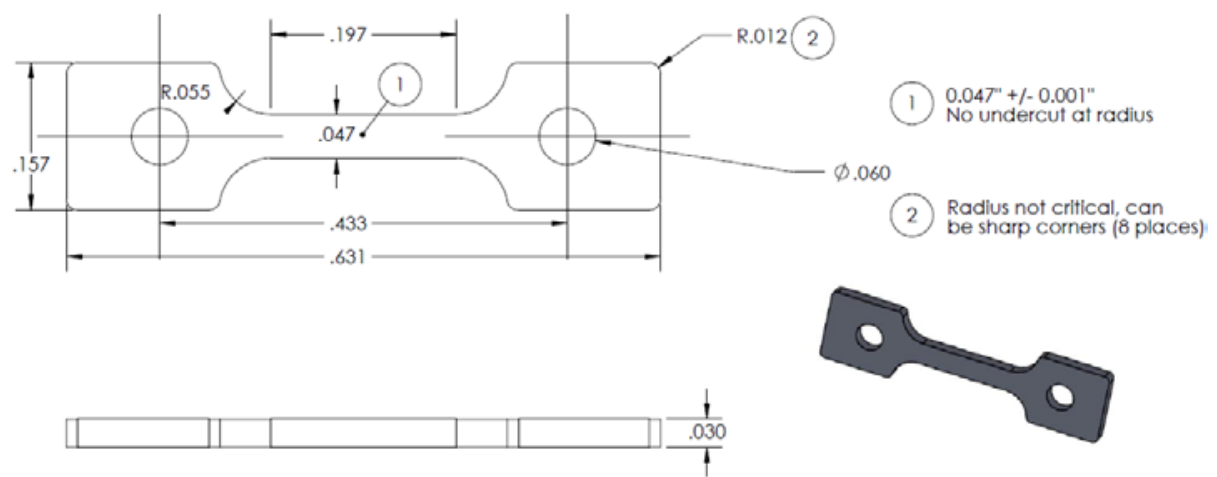

Figure 2. Schematic of miniature tension test samples with dimensions. The samples were cut using EDM.

\section{Results}

Engineering stress-strain curves obtained at room temperature are shown in Figure 3. SEM images of the fracture surfaces are also shown. Both images show typical ductile fracture surfaces that contain dimples. Yield strength values were measured at $0.2 \%$ offset. The fitting 
parameters were also shown on the graph inlets. ORNL A shows a higher yield strength compared to ORNL B. Both show similar total elongation values 20\%.
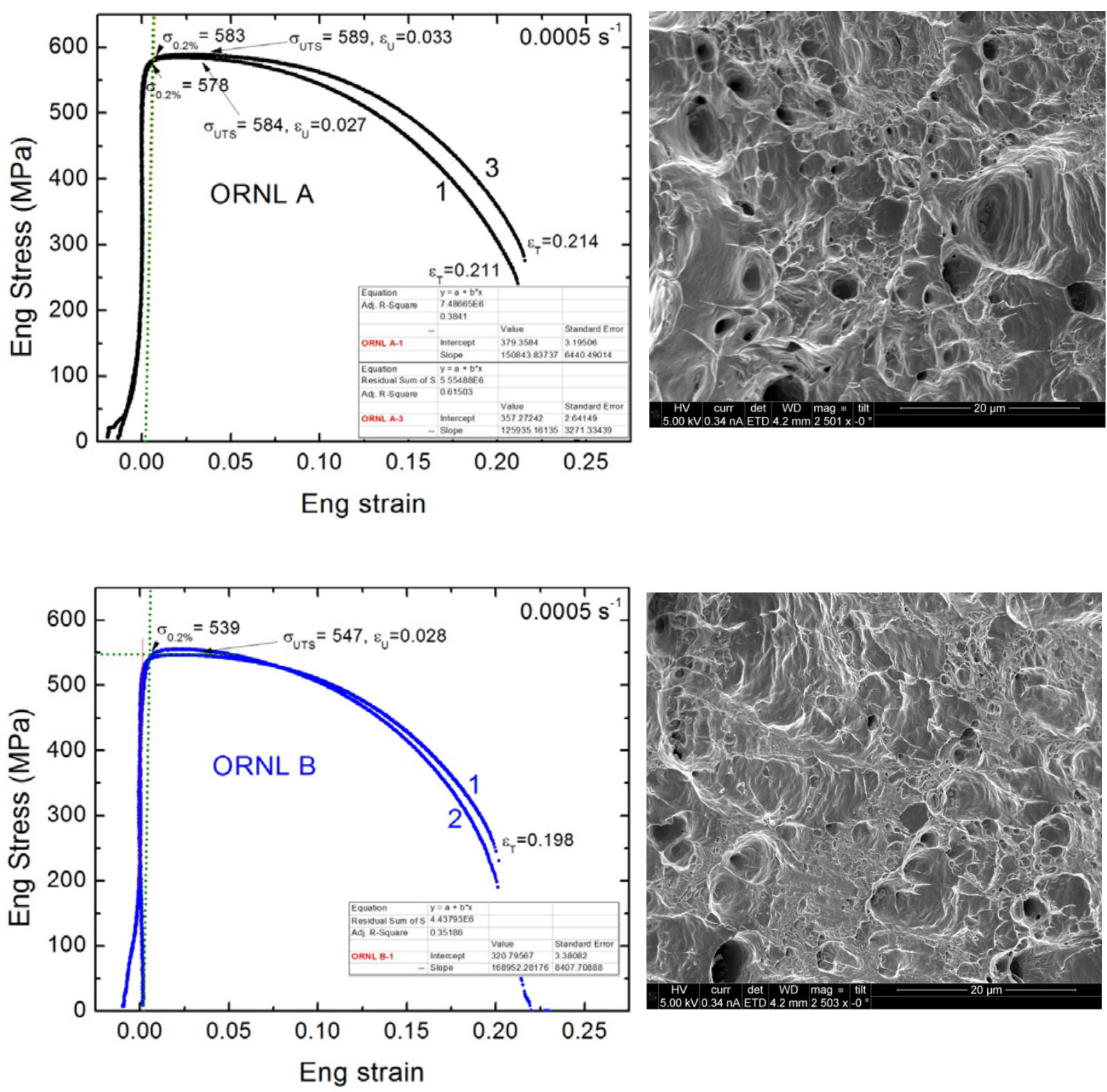

Figure 3. Engineering stress-strain curves of ORNL A (top) and B (bottom) samples are shown. Corresponding SEM images show dimples, typical of ductile fracture surface.

High temperature testing

Engineering stress-strain curves obtained at 300 and $600^{\circ} \mathrm{C}$ are shown in Figures 4 and 5. Yield strength values were measured at $0.2 \%$ offset. The fitting parameters to the linear portion 
of the stress-strain curves were also shown on the graph inlets. ORNL A shows higher yield strength compared to ORNL B.

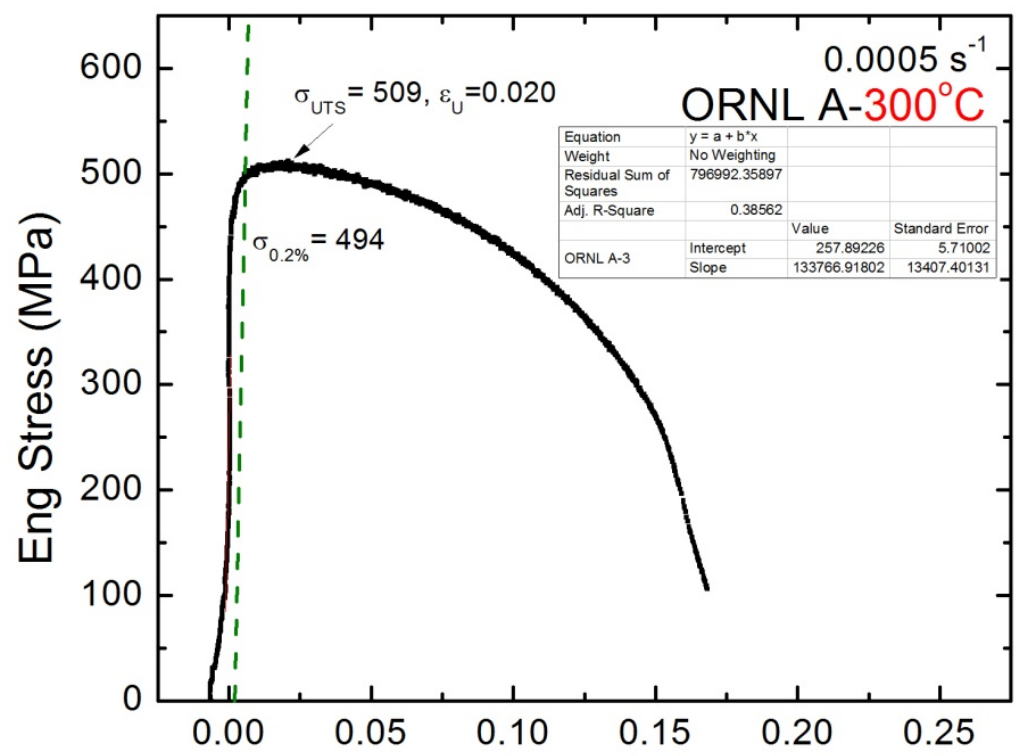

Eng strain

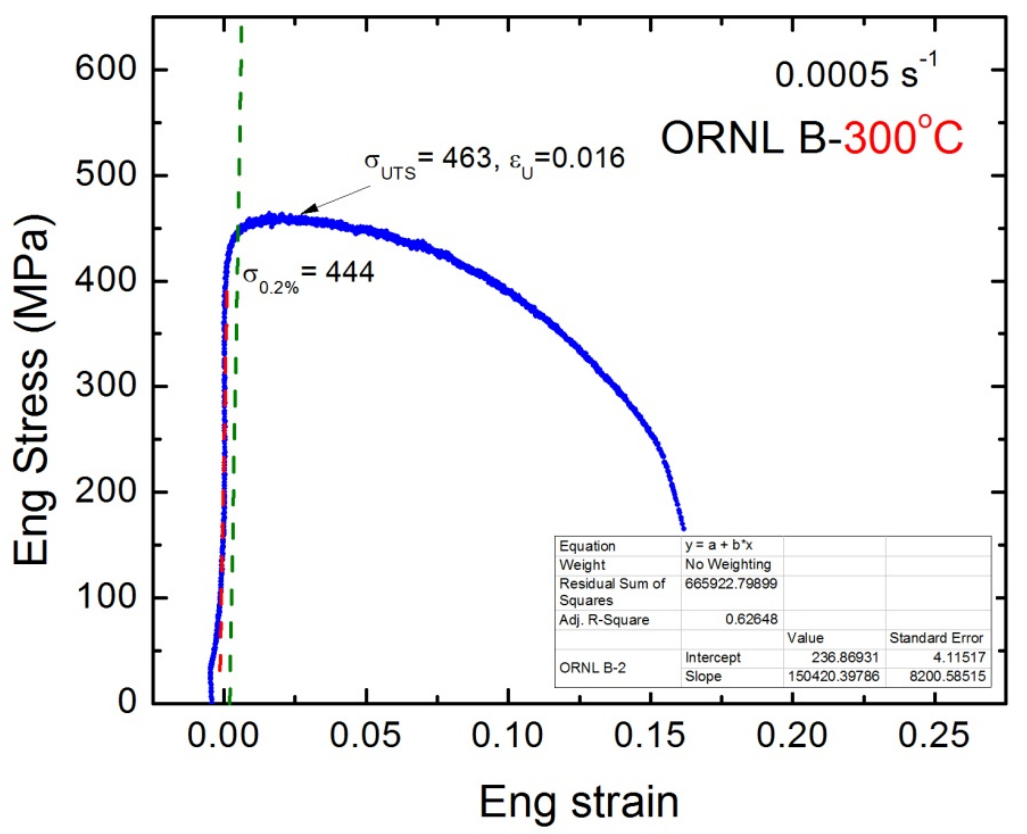

Figure 4. Engineering stress-strain curves of ORNL A\&B alloy tested at $300^{\circ} \mathrm{C}$. 


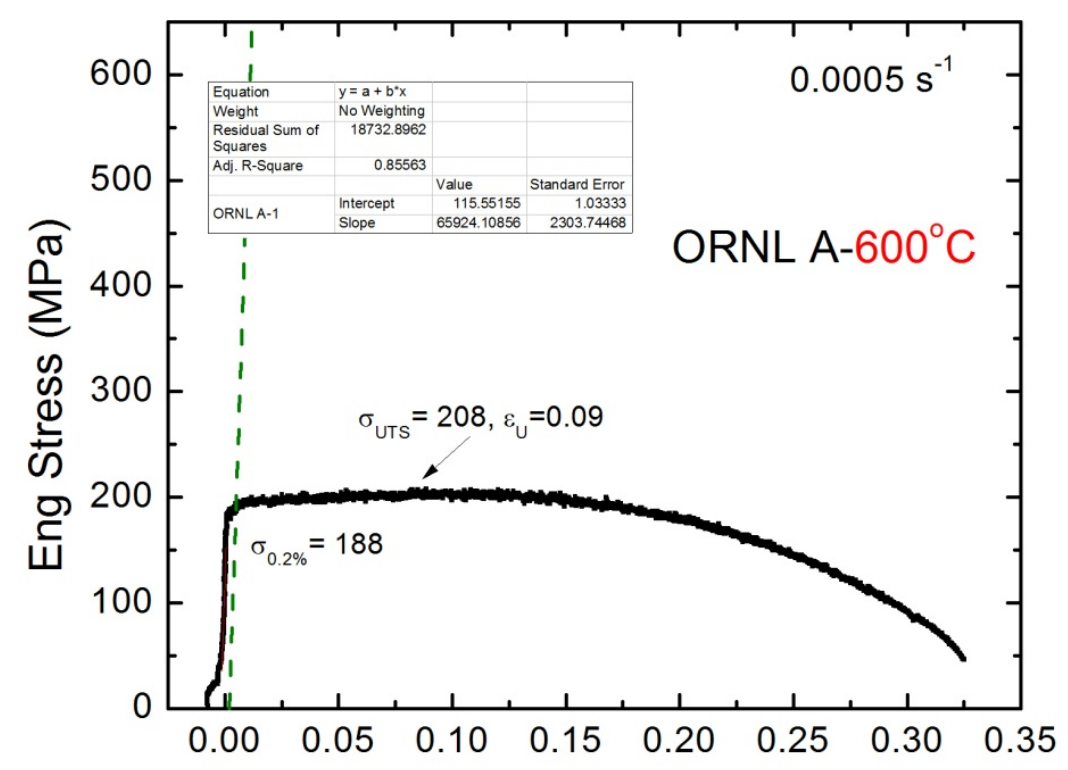

Eng strain

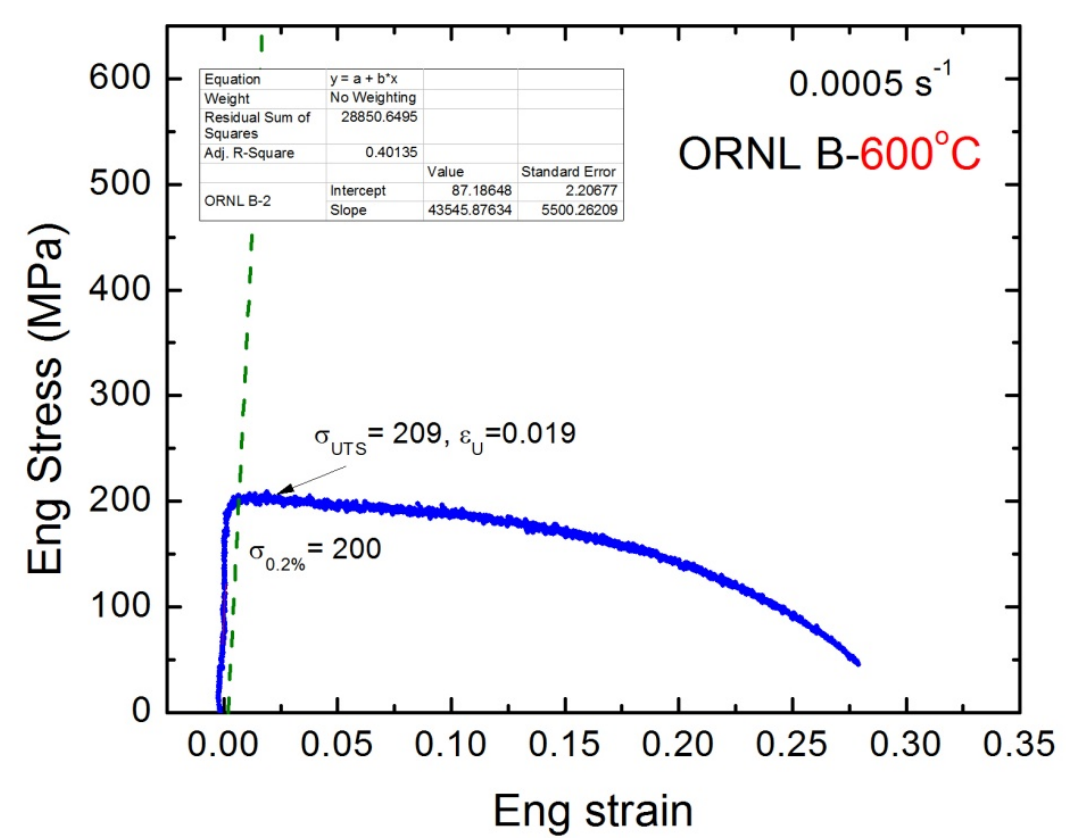

Figure 5. Engineering stress-strain curves of ORNL A and B alloys tested at $600^{\circ} \mathrm{C}$. 


\section{Summary}

Two FeCrAl based alloys were tested in tension at room temperature and elevated temperatures (300 and $600^{\circ} \mathrm{C}$ ). Typical tensile behavior is observed for this class of alloys. The results are summarized in Table 2.

Table 2. Summary of the tensile tests on ORNL A \&B at 23, 300, and 600C.

\begin{tabular}{|c|c|c|c|c|}
\hline $23^{\circ} \mathrm{C}$ & $\sigma_{Y}(\mathbf{M P a})$ & $\sigma_{\text {UTS }}(\mathbf{M P a})$ & $\varepsilon_{\text {uniform }}(\%)$ & $\varepsilon_{\text {total }}(\%)$ \\
\hline ORNL A & 581 & 587 & 3.3 & 21 \\
\hline $\begin{array}{c}\text { ORNL B } \\
300^{\circ} \mathrm{C}\end{array}$ & 539 & 547 & 2.8 & 19.8 \\
\hline ORNL A & 485 & 493 & 1.9 & 17.5 \\
\hline $\begin{array}{l}\text { ORNL B } \\
600^{\circ} \mathrm{C} \\
\end{array}$ & 453 & 470 & 1.7 & 15.9 \\
\hline ORNL A & 188 & 207 & 9 & 32.1 \\
\hline ORNL B & 200 & 209 & 1.9 & 28.6 \\
\hline
\end{tabular}

\section{References}

1. Engkvist, J., et al., Alumina Scale Formation on a Powder Metallurgical FeCrAl Alloy (Kanthal APMT) at 900-1,100 A degrees C in Dry O-2 and in O-2 + H2O. Oxidation of Metals, 2010. 73(1-2): p. 233-253.

2. Terrani, K.A., S.J. Zinkle, and L.L. Snead, Advanced oxidation-resistant iron-based alloys for LWR fuel cladding. Journal of Nuclear Materials, (0).

3. Yamamoto, Y., ORNL FeCrAl Alloy Development and Plate Processing for ATF Partners, 2013, Oak Ridge National Laboratory. 